\title{
Shifting Burdens: The Failures of the Deinstitutionalization Movement from the 1940s to the 1960s in American Society
}

Ellen Sutherland

\begin{abstract}
Shifting Burdens explores the process and features of mental patient deinstitutionalization as it occurred in America in the 1950s and 1960s. This paper examines the disillusionments American society had with mental institutions, such as faltering standards of care, staff failures, and inadequate treatment options. These issues resulted in the movement towards deinstitutionalization, resulting in the burden of care for displaced mental patients being shifted onto community homes and patients families. Shifting Burdens challenges the notion that deinstitutionalization at the time was a successful endeavour, as the question of care for mental patients continues to exist today.
\end{abstract}

The process of mental patient deinstitutionalization in America has occurred several times since the 1800s, though the episode beginning in the 1940s and into the 1960s is distinct among these due to its focus on patient's rights and community care. This particular wave of deinstitutionalization occurred due to disillusionment with quality of care in light of increasing awareness for human rights in the 1960s and resulting in changing perceptions of quality of life, patient autonomy, and changing government policy. The demands for reform caused a shift in policy and practice to varying degrees of success. Through analysis of the larger social changes and perceptions around life and autonomy of mental patients, the deinstitutionalization wave from the 1940s to 1960 s was ultimately a failure in meeting its goals of improving life for patients.

The deinstitutionalization of mental patients in the 1950s and 1960s was an attempt to "redefine the boundaries of the social welfare [and] mental health" systems in the United States, as well as "shift[ing] responsibility for dependent populations from one institutional setting" into a community based setting. ${ }^{1}$ Mental patients were viewed as "guiltless patient-prisoners" trapped within the institutions and segregated from the broader society. ${ }^{2}$ While patients were perceived as incapable of caring for themselves, there was still a belief that these individuals should have a reasonable standard of living and quality of life.

Historians often look to three critical failings of American institutions in the 1940s that would ultimately result in the shift towards community institutions: disillusionment with treatment, an absence of a curative effect, and the violation of human rights. ${ }^{3}$ One of the earliest articulations of America's dissatisfaction with the mental institution system was expressed in Albert Maisel's article for Life magazine, titled Bedlam 1946. The article focused primarily on the degenerating conditions of living and care in America's asylums.

Maisel's article, subtitled "U.S. Mental Hospitals are a Shame and a Disgrace," was an expose of two mental hospitals: Pennsylvania's Byberry and Ohio's Cleveland State. Maisel criticizes the "starvation diets," under-staffing, and widespread abuse occurring in the hospitals,

\footnotetext{
${ }^{1}$ Morissey et. al. "Care and Treatment of the Mentally Ill," 13.

${ }^{2}$ Maisel, "Bedlam 1946." Life Magazine, May 1946, 103.

${ }^{3}$ Tuntiya, "The Forgotten History," 5-6.
} 
supplementing his criticism with first-hand accounts of the dismal hospital standards. One such account from an Ohio state hospital recalls the commonplace abuse:

An attendant and I were sitting on the porch watching the patients. Somebody came along sweeping and the attendant yelled at a patient to get up off the bench so that the workerpatient could sweep. But the patient did not move. The attendant jumped up with an inchwide restraining strap and began to beat the patient in the face and on top of the head. 'Get the hell up...!' It was a few minutes -- a few horrible ones for the patient -- before the attendant discovered that he was strapped around the middle to the bench and could not get up. ${ }^{4}$

This account is just one of many statements recounting abuse provided in Maisel's article. In addition, he also supplies numerous photographs of the appalling living conditions, including snapshots of patients laying unattended on the ground, or sitting nude in a large hall. When coupled with the verbal accounts of mental hospital life, Maisel succeeded in providing American society with a true look into the true world of the institutional system.

A key argument of Bedlam 1946 states that while the war was not a direct cause of the failing institutions, it had just "accentuat[ed] long-existing failings". These failings he highlighted as few and under trained staff, abuse, poor living conditions and exceedingly low improvement rates after treatment. It was in the years following World War II that a similar "growing pessimism and therapeutic nihilism" began spreading through the world of psychiatry, in both theory and practice. ${ }^{5}$ Many young American men returning from war found themselves mentally unwell upon returning home, spurring a "renewed interest in prevention" as well as optimism for new and briefer treatment options that kept individuals from isolated institutions. ${ }^{6}$ With the innumerable accounts of human rights violations during the war, there became increasing criticism around the intolerable conditions in America's mental hospitals. ${ }^{7}$

The Nazi euthanasia program, Aktion T-4, was carried out from 1939 until 1941 and implemented the process of euthanizing the physically and mentally disabled, the same individuals that America was housing in her institutions. It wasn't until 1941 that Americans were made aware of Aktion T-4's existence, when the T-4 program had already devolved into a de-centralized and unregulated system of ending killing the aforementioned groups by starvation, exhaustion and other inhumane actions. Upon learning of the horrors of concentration camps and forced euthanasia, Americans began to re-evaluate how they were treating their own mentally ill individuals. Attention was turned to the appalling quality of care American mental patients were receiving, and society began to question why they were treating their own citizens in a manner reflective of Nazi atrocities.

The quality of care was also reflective of staffing failings. Maisel suggested having "one attendant" for "as many as 400 mentally deranged" patients lead to staff "ceas[ing] to strive for cures." Beatings were also commonplace, another result of "poorly trained and shamefully

\footnotetext{
${ }^{4}$ Maisel, "Bedlam 1946." Life Magazine, May 1946, 105.

${ }^{5}$ Morissey et. al. "Care and Treatment of the Mentally Ill," 18.

${ }^{6}$ Ibid., 20.

${ }^{7}$ Chafetz et. al. "Deinstitutionalization in the United States," 50.
} 
underpaid employees" who were tasked with trying to maintain care for hundreds of institutionalized individuals that "they fear[ed] and despis[ed]." "While deinstitutionalization was primarily a question of patient's quality of life, quality of life for the care workers needed to be examined as well. Institutions were becoming "warehouses" for the mentally ill, overcrowded with a low quality of care and exceedingly expensive to keep in operation. ${ }^{9}$

With inadequate care providers came inadequate treatments. Patients in the late 1940s who entered the institution system were typically expected to remain there for the remainder of their lives as curing was viewed as an impossibility; institutionalization was typically seen as a solution, not a cure. Psychologists viewed institutions as permanent and final arrangements for patients that they would spend the remainder of their lives in. ${ }^{10}$ While improvement was always something strived for, "annually, for every 100 patients, fewer than 12 [were] discharged as improved." $" 11$

Individuals living in the mental institutions were, furthermore, subject to inadequate living conditions, with most facilities "degenerat[ing] into little more than concentration camps." 12 "Beatings and murders" were "hardly the most significant of the indignities" to be inflicted upon the "guiltless patient prisoners." Starvation was common, as well as overcrowding, forced restraint, inadequate clothing, and slave labour. ${ }^{13}$ Maisel is quick to condemn American mental institutions as "man-made hells," a commonly held belief amongst many Americans - especially mental health reformers - moving forward into the 1950s and 1960s.

After heavy criticisms echoing that of Maisel's emerged in the 1940s, Americans began to believe that the mental health system was in dire need of reform. The movement of deinstitutionalization that occurred moving forward into the $1950 \mathrm{~s}$ began in a similar manner to previous movements to release patients from institutions, with the "promise that early treatment would prevent personal and societal problems." 14 Reform began in the 1950 s with some claiming that early treatment coupled with the use of innovative antipsychotic medications was the path to take to be able to finally cure patients and remove them from facilities that were degrading so quickly. ${ }^{15}$ Psychotropic medications emerging in the mid 1950s pharmaceutical market gave doctors a new avenue of treatment. As well, hospitals opened acute care units and aftercare clinics to serve those who were now being treated with these newly developed drugs and could be released from their institutions. ${ }^{16}$ Reformers believed that the chronicity of the inflictions plaguing institutionalized patients could simply be prevented earlier, and therefore hospitals would be rendered obsolete. ${ }^{17}$

\footnotetext{
${ }^{8}$ Maisel, "Bedlam 1946." Life Magazine, May 1946, 107.

${ }^{9}$ Dumont et. al. "Deinstitutionalization in the U.S. and Italy," 65.

${ }^{10}$ Morissey et. al. "Care and Treatment of the Mentally Ill," 13.

${ }^{11}$ Maisel, "Bedlam 1946." Life Magazine, May 1946, 112.

${ }^{12}$ Ibid., 102.

${ }^{13}$ Ibid., 103.

${ }^{14}$ Morissey et. al. "Care and Treatment of the Mentally Ill," 13.

${ }^{15}$ Ibid., 20.

${ }^{16}$ Ibid., 20.

${ }^{17}$ Ibid., 19 .
} 
The objectives set forth in the 1950s proved to be difficult to fulfill. Early recognition and treatment was not always an option for individuals, especially in the cases of sudden-onset psychosis, physical defects, or mental challenge occurring at birth. While early treatment was a step towards satisfying needs of patients, it was ultimately the arrival of the 1960s - and an increased sensitivity to individual human rights and liberties - that allowed deinstitutionalization truly come to fruition as a community-based care movement. After almost half a century of political unrest, multiple wars, Nazism, and violent civil rights inequality, American society sought to move to equalize all it's individuals, including those who were institutionalized. The logic behind the movement was considerable: humans, as social creatures, could be aided or cured by interactions with society. ${ }^{18}$ Especially those under mental care.

The 1960s saw the height of deinstitutionalization movement in practice as well as policy, and "reassessed the history of incarceration of the mentally ill in the context of the development of new social control mechanisms in society." 19 There was a shift to community based care, changes in public perception of mental patients and treatment, as well as policy changes deriving from individual state's seeking to reduce costs of institutionalization. ${ }^{20}$

The deinstitutionalization movement had three key goals moving forward into the 1960s: to relocate individuals from their poor conditions in institutions and into more humane settings, to minimize long term hospitalization, and to reduce costs associated with institutionalization. ${ }^{21}$ The solution proposed to meet these goals was to shift institutionalized patients from the hospitals to the community. The belief was that by creating community treatment programs, such as treatment facilities, supervised homes, and community psychiatric teams, patients could receive the same services that were provided at hospitals, while integrating into the community and improving their quality of life. ${ }^{22}$ Supporters of deinstitutionalization viewed the community as a more humane setting for individuals and could provide them with the treatment and rehabilitation necessary for reintegration into society. ${ }^{23}$ Providing local services to mental patients was suggested as the best alternative to mental institutions as "communities could furnish all the services once offered in institutions" while also being able to "provide the leadership and resources to do so." 24

The U.S. Government responded favorably to society's push towards deinstitutionalization and viewed it as a chance to decrease expenditures, as there were too large a number of patients in the system for the programs to be cost effective. ${ }^{25}$ The government originally began to support the deinstitutionalization movement in the late 1950s, supporting reformer's original push for early treatment by creating the 1955 Mental Health Study Act. This act allowed the study and analysis of mental health patients to attempt to address their needs early and promote curative care.

\footnotetext{
${ }^{18}$ Wolins, et. al. "Deinstitutionalization and the Benevolent Asylum," 605.

${ }^{19}$ Rothman 1971 in Tuntiya, "The Forgotten History," 4.

20 "A Brief History of Mental Illness."

${ }^{21}$ Chafetz et. al. "Deinstitutionalization in the United States," 49.

22 "A Brief History of Mental Illness."

${ }^{23}$ Chafetz et. al. "Deinstitutionalization in the United States," 50.

${ }^{24}$ Ibid., 51.

${ }^{25}$ Tuntiya, "The Forgotten History," 42.
} 
Policy in the 1960s was more focused on the liberties and quality of life of the individual patients, with an emphasis on integrating patients back into society. The Community Health Services and Facilities act was established in 1961 and increased the funds available for community buildings and research. Shortly after, in 1963, the Mental Retardation and Community Mental Health Centers Construction Act (also referred to as the Community Mental Health Act) finally moved forward on the construction of community centers in which individuals could seek care and support for their maladies. ${ }^{26}$ The 1963 Community Mental Health Act was the most significant piece of legislation enacted as part of the deinstitutionalization movement. ${ }^{27}$ Under Kennedy - who's lobotomized sister Rosemary provided him with a personal investment in care for mentally disabled - the Community Mental Health Act resulted in the closure of state hospitals. ${ }^{28}$ This act in turn created a network of federally supported community healthcare centers across America to replace the closed facilities. In the same year, the National Institute of Mental Health was established to monitor the new community programs as well as fund research for the betterment of those in need of care ${ }^{29}$ By 1965, the Medicare and Medicaid systems were established and further assisted in providing community services for individuals of all income brackets, extending the right to mental healthcare to all Americans and "providing further incentive for the development of a pluralistic community based system." 30

Ultimately, the government's uptake of the social push for community based care was due to cost savings. State governments viewed deinstitutionalization as an "opportunity to divest themselves of the financial burden of public hospitals." 31 Deinstitutionalization did demonstrate several successes in the years after these legislations occurred, such as the $65 \%$ decrease in admitted patients between 1955 and 1977 while offering less restrictive care options. ${ }^{32}$ However, the creating of these community spaces by which to treat individuals resulted in unintended consequences in follow up treatment as well as shifting burdens of care.

After the government began enacting community-centered policies, innovative community programs were established. The Fairweather Lodge is a notable facility, established in 1963. It acted as a treatment and living facility that provided patients with work opportunities - to integrate individuals back into functioning society as well as providing required care and facilities to live in. However, programs like the Fairweather Lodge heavily depended on a highly motivated and committed staff; without the investment by treatment workers, results were not always favorable. ${ }^{33}$

Many critics of institutions in the late 40s and 50s "failed to consider the range of chronic patients". ${ }^{34}$ Public mental hospitals remaining after deinstitutionalization aimed to be short-term care providers, releasing $80 \%$ of their patients within 3 months of their admission so as to not

\footnotetext{
26 "Community Mental Health Act."

${ }^{27}$ Chafetz et. al. "Deinstitutionalization in the United States," 48.

28 "A Brief History of Mental Illness."

${ }^{29}$ Chafetz et. al. "Deinstitutionalization in the United States," 48.

${ }^{30}$ Ibid., 49.

${ }^{31}$ Ibid., 52.

${ }^{32}$ Piat, "Deinstitutionalization of the Mentally Ill," 205.

${ }^{33}$ Chafetz et. al. "Deinstitutionalization in the United States," 54.

${ }^{34}$ Ibid., 52.
} 
become long-term treatment centers as the previous institutions were. ${ }^{35}$ From 1955 to 1980 , there was a $75 \%$ decrease in residence at public hospitals, as under new and more stringent criteria, only the most dire and impaired cases were admitted. ${ }^{36}$ Though most patients were free to reside away from institutions in the 1960s, this generally resulted in increased numbers of "revolving door patients", who continually returned for episodic care over time, as they were not 'cured'. 37 The cases of these patients were not severe enough to require hospitalization, so accommodations needed to be made throughout the healthcare system. ${ }^{38}$ Similar cases of ambulatory care of mental patients in the community increased to $70 \%$ of all psychiatric cases being treated in this manner by 1975 , though these were usually those with less severe or nondangerous issues. However, the increased ambulatory care did little to assist those requiring more support that outpatient therapy could provide. ${ }^{39}$ By the 1970 s two thirds of all patients treated in the community returned for continued care, while many patients received no follow up care at all. ${ }^{40}$

Critics of the deinstitutionalization movement often point out that the movement did not actually improve quality of treatment for the patients, but rather it simply shifted the burden of care from hospitals and institutions onto the community and families of the patients. Individuals with severe mental ailments who would previously have been sent to institutions were forced to remain dependent on their families. ${ }^{41}$ This phenomenon of shifting care from institution to community and family is referred to as transinstitutionalization. The burden of care was shifted not only onto families, but resulted in the creation of "mini institutions" as well. ${ }^{42}$ Elderly institutionalized patients, especially, were moved into community nursing homes; by the 1970s, the number of elderly in psychiatric facilities had reduced to up to $40 \%$ in some areas because they had been transferred into nursing homes. ${ }^{43}$ As well, boarding homes were another form of "mini institution" that appeared during the years following deinstitutionalization, though many were unregulated and unlicensed, resulting in sub-par living conditions. ${ }^{44}$ Many homes excluded the mentally disabled and only catered to the mentally ill, so the former were displaced to other areas, ultimately resulting in the increase of urban homelessness in the $1970 \mathrm{ss}^{45}$

Some patients previously institutionalized were able to live independently after deinstitutionalization though with heavy reliance on public services to maintain a decent standard of living. ${ }^{46}$ Following the closure of state institutions, the government assumed that "certain private services would develop in response to deinstitutionalized patient's needs." 47 Services provided by the hospitals - namely living space, food, and continued supervision - were now expected to be provided by the community. Though deinstitutionalization aimed to give patients

\footnotetext{
${ }^{35}$ Chafetz et. al. "Deinstitutionalization in the United States," 55.

${ }^{36}$ Ibid., 53.

${ }^{37}$ Ibid., 53.

${ }^{38}$ Ibid., 54.

${ }^{39}$ Ibid., 54.

${ }^{40}$ Ibid., 53 ..

${ }^{41}$ Piat, "Deinstitutionalization of the Mentally Ill," 205.

${ }^{42}$ Ibid., 206.

${ }^{43}$ Chafetz et. al. "Deinstitutionalization in the United States," 53.

${ }^{44}$ Morissey et. al. "Care and Treatment of the Mentally Ill," 55.

${ }^{45}$ Ibid., 55.

${ }^{46}$ Ibid., 57.

${ }^{47}$ Chafetz et. al. "Deinstitutionalization in the United States," 55.
} 
a higher quality of life for patients, it proved to be only a minimal increase in some regards. Many had to rely on government benefits or residence placements, funded through both the private and public sector. ${ }^{48}$ Therefore, while the government aimed to reduce costs by closing mental institutions, they were still burdened with caring for these individuals who were simply displaced from institutions without actually being cured. While the costs of long-term institutionalization and care from the 1940s were ultimately reduced, the per capita costs increased in the form of funding the "mini institutions" and community mental health centers, as well as medicare and medicaid programs. ${ }^{49}$ Not only was the burden of care shifted, but the cost burden for the state was also shifted from state funded institutions to federal programs. ${ }^{50}$

The 560000 Americans institutionalized in the 1950s decreased to only 130000 by the onset of the $1980 \mathrm{~s}^{51}$ While it is tempting to view these numbers as a success of deinstitutionalization, the movement was ultimately a failure. While the movement was able to provide resolution for the inhuman conditions of earlier institutions, other problems appeared instead; inadequate follow up care, shifting burdens of care, and high costs to sustain treatments were all consequences of the closure of mental institutions. Deinstitutionalization did not succeed in creating a communitybased care approach; rather, it simply shifted the burden of care from hospitals and institutions onto the community and families of the patients. The ultimate evidence of this particular deinstitutionalization wave's failure is the enduring problem of mental patient treatment centers and care in our modern society. Even though the deinstitutionalization movement following the 1940s made tremendous progress in increasing the quality of life and treatment for patients, it was by no means an end-all solution to the question of mental patient care.

\footnotetext{
${ }^{48}$ Morissey et. al. "Care and Treatment of the Mentally Ill," 57.

${ }^{49}$ Morissey et. al. "Care and Treatment of the Mentally Ill," 58.

${ }^{50}$ Ibid., 58.

51 "A Brief History of Mental Illness."
} 


\section{Bibliography}

Chafetz, Linda, Howard H. Goldman and Carl Taube. "Deinstitutionalization in the United States.” International Journal of Mental Health, 11.4 (1982-1983): 48-63

Dowbiggen, Ian. A Merciful End: The Euthanasia Movement in Modern America. NewYork: Oxford University Press, 2003.

Dumont, Matthew P. And Dora M. Dumont. "Deinstitutionalization in the U.S. and Italy: A Historical Survey.” International Journal of Mental Health. 37.4 (2008-2009): 61-70.

Maisel, Albert Q. “Bedlam 1946,” Life Magazine, May 6, 1946.

Morissey, Joseph P. and Howard Goldman. "Care and Treatment of the Mentally Ill in the U.S.: Historical Developments and Reforms". Annals of the American Academy of Political and Social Science. 484 (1986): 12-27.

National Council for Behavioral Health. "Community Mental Health Act." 2015. Accessed September 3, 2015.

Piat, Myra. "Deinstitutionalization of the Mentally Ill: Theory, Policy and Practice." Canadian Social Work Review. 9.2 (1992): 201-213.

Tuntiya, Nana. "The Forgotten History: The deinstitutionalization movement in the mental health care system in the United States." (Masters diss., University of Southern Florida, 2003).

Unite for Sight. "A Brief History of Mental Illness and the U.S. Mental Healthcare System.” 2013. Accessed November 8, 2014.

Wolins, Martin and Yochanan Wozner. "Deinstitutionalization and the Benevolent Asylum.” Social Service Review. 51.4 (1977): 604-623. 